\title{
Examining the effects of comorbidities on disease-modifying therapy use in multiple sclerosis OPEN
}

Tingting Zhang, MD, $\mathrm{PhD}$

Helen Tremlett, $\mathrm{PhD}$ Stella Leung, MSc Feng Zhu, MSc Elaine Kingwell, PhD John D. Fisk, PhD Virender Bhan, MBBS

Trudy L. Campbell, MN, NP

Karen Stadnyk, MSc

B. Nancy Yu, MD, PhD

Ruth Ann Marrie, MD, $\mathrm{PhD}$

For the CIHR Team in the Epidemiology and Impact of Comorbidity on Multiple Sclerosis

Correspondence to

Dr. Marrie:

rmarrie@hsc.mb.ca

Supplemental data at Neurology.org

\section{ABSTRACT}

Objective: Comorbidities are common in multiple sclerosis (MS) and adversely affect health outcomes. However, the effect of comorbidity on treatment decisions in MS remains unknown. We aimed to examine the effects of comorbidity on initiation of injectable disease-modifying therapies (DMTs) and on the choice of the initial DMT in MS.

Methods: We conducted a retrospective observational analysis using population-based health administrative and linked clinical databases in 3 Canadian provinces. MS cases were defined as any individual with $\geq 3$ diagnostic codes for MS. Cohort entry (index date) was the first recorded demyelinating disease-related claim. The outcomes included choice of initial first-line DMTs and time to initiating a DMT. Logistic and Cox regression models were used to examine the association between comorbidity status and study outcomes, adjusting for sex, age, year of index date, and socioeconomic status. Meta-analysis was used to estimate overall effects across the 3 provinces.

Results: We identified 10,698 persons with incident MS, half of whom had $\geq 1$ comorbidities. As the total number of comorbidities increased, the likelihood of initiating a DMT decreased. Comorbid anxiety and ischemic heart disease were associated with reduced initiation of a DMT. However, patients with depression were $13 \%$ more likely to initiate a DMT compared to those without depression at the index date (adjusted hazard ratio 1.13; 95\% confidence interval 1.00-1.27).

Conclusions: Comorbidities are associated with treatment decisions regarding DMTs in MS. A better understanding of the effects of comorbidity on effectiveness and safety of DMTs is needed. Neurology ${ }^{\circledR}$ 2016;86:1287-1295

\section{GLOSSARY}

aHR = adjusted hazard ratio; $\mathbf{B C}=$ British Columbia; $\mathbf{C l}=$ confidence interval; DMT = disease-modifying therapy; ICD-9/ $\mathbf{1 0}=$ International Classification of Diseases-9 or 10; IHD = ischemic heart disease; $\mathbf{M B}=$ Manitoba; $\mathbf{M S}=$ multiple sclerosis; NS = Nova Scotia; SES = socioeconomic status

Multiple sclerosis (MS) is a chronic disease of the CNS. ${ }^{1}$ The emergence of disease-modifying therapies (DMTs) in the 1990s advanced MS management, as randomized clinical trials demonstrated reductions in relapse rates and disability progression over short periods. ${ }^{2}$ Comorbidities are common in individuals with chronic diseases, including MS, ${ }^{3}$ and adversely affect health outcomes. ${ }^{4-8}$ For example, there are concerns regarding increased hepatotoxicity due to drugdrug interactions between interferon- $\beta$ and lipid-lowering agents. ${ }^{9}$ Fingolimod is associated with sudden cardiac-related death, and is contraindicated in persons with preexisting cardiac disease or stroke. ${ }^{10}$ In other chronic diseases such as hypertension and cancer, comorbidities may affect treatment decisions and further affect disease outcomes, ${ }^{5}$ by changing the choice of whether to start treatment and the specific choice of treatment. ${ }^{11,12}$ However, no studies have

\footnotetext{
From the Department of Medicine, Division of Neurology and Centre for Brain Health (T.Z., H.T., F.Z., E.K.), University of British Columbia, Vancouver; Department of Community Health Sciences (S.L., B.N.Y., R.A.M.), University of Manitoba, Winnipeg; Departments of Medicine (J.D.F., V.B., T.L.C.) and Psychiatry (J.D.F.) and School of Nursing (T.L.C.), Dalhousie University, Halifax, Nova Scotia; and Queen Elizabeth II Health Sciences Centre (J.D.F., V.B., T.L.C., K.S.), Nova Scotia Health Authority, Halifax, Canada.

Coinvestigators are listed on the Neurology ${ }^{\circledR}$ Web site at Neurology.org.

Go to Neurology.org for full disclosures. Funding information and disclosures deemed relevant by the authors, if any, are provided at the end of the article. The Article Processing Charge was paid by the Canadian Institutes of Health Research.

This is an open access article distributed under the terms of the Creative Commons Attribution-NonCommercial-NoDerivatives License 4.0 (CC BY-NC-ND), which permits downloading and sharing the work provided it is properly cited. The work cannot be changed in any way or used commercially.
} 
examined comorbidity and treatment decisions in patients with MS. We examined the effects of comorbidity on the use of DMTs in MS with respect to whether comorbidities delayed initiation of a DMT or affected the choice of the initial DMT. We hypothesized that the presence of comorbidities would reduce DMT use and influence the choice of DMT for those with MS.

METHODS Study design and data sources. We followed a common protocol to conduct this retrospective cohort study in 3 Canadian provinces (British Columbia [BC], Manitoba [MB], and Nova Scotia $[\mathrm{NS}])$.

We used prospectively collected, linked administrative (health claims) and clinical data in each province. Details regarding administrative data used are summarized in Methods appendix e-1 on the Neurology ${ }^{\circledR}$ Web site at Neurology.org; these databases have been used extensively previously. ${ }^{13-15}$ Data linkage was performed at the individual level using a unique personal health number, following which the data were anonymized for analysis. Due to privacy regulations that prevent line level data from leaving the province of origin, analyses were performed in parallel at each site.

Standard protocol approvals, registrations, and patient consents. The research ethics boards at each site approved the study, while access to administrative data was approved by the relevant body within each province (BC Ministry of Health and Data Stewardship Committee, the Manitoba Health Information Privacy Committee, and the Nova Scotia Department of Health and Wellness).

MS case definition. Using physician and hospital claims in each province, we defined MS cases as any individual with $\geq 3$ codes for MS using ICD-9/10 (340/G35). This case definition has a positive predictive value of $95 \%$ (95\% confidence interval [CI] 0.91-0.97). ${ }^{14}$ Cohort entry (i.e., the index date) was defined as the first recorded MS or demyelinating disease-related claim (ICD-9/10 377.3, 323, 341.9, 341.0/H46, G37, G36.9, G36.0). ${ }^{14}$ A 5-year run-in period was required to ensure all cases were incident, during which time residency in the province was required and no MS or demyelinating disease codes were allowed. Cases were adults ( $\geq 18$ years by cohort entry) with the potential incident date ranges determined by the data availability in each province (1989-2012 in MB, 1995-2012 in NS, and 1996-2010 in BC). Table e-1 shows patient selection. Patients were followed until the earliest of DMT initiation, death, emigration from the relevant province, or end of the study (December 31, 2010 in BC; March 31, 2012 in MB and NS).

Comorbidity status. We applied previously validated algorithms ${ }^{16}$ to identify whether individuals ever met the case definition for an individual comorbidity (Methods appendix e-1). We used the first claim for the comorbidity as the date of diagnosis. This date was also used to determine whether a comorbidity was present or absent by the index date, and if absent, whether it developed after the index date. Once a comorbidity occurred, it was considered present for the rest of the follow-up. The comorbidities of interest included physical conditions (diabetes, hypertension, hyperlipidemia, ischemic heart disease [IHD], chronic lung disease, epilepsy) and mental conditions (anxiety, depression, bipolar disorder). These comorbidities were selected based on the availability of case definitions with adequate validity, ${ }^{15,16}$ their effect on other MS outcomes (e.g., disability, quality of life), and potential clinical relevance in the MS population. Comorbidity status at the index date was examined in 2 ways. First, we considered the total number of comorbidities. Because this variable did not meet the proportional hazards assumption, we included the number of comorbidities as a time-dependent continuous variable. Second, we considered the presence of individual comorbidities. Comorbidity status over the entire study period (i.e., comorbidities at the index date and incident comorbidities occurring after the index date) was examined as a time-varying variable: the total number of comorbidities listed above and the presence vs absence of each individual comorbidity at the earliest diagnostic date.

Outcome. As oral DMTs were not approved during the study period, our analysis focused on the first-line injectable DMTs. The outcome of interest was initiation of a first-line DMT, defined as $\geq 1$ filled prescription of interferon- $\beta$ (approved in July 1995 in Canada) or glatiramer acetate (approved in September 1997). DMT use was examined as (1) "ever vs never" and (2) choice of initial DMT (glatiramer acetate vs interferon- $\beta$ ).

Statistical analyses. Potential confounders, measured at the index date, included sex (male as reference group); age, grouped as 18-29 (reference group), 30-39, 40-49, and $\geq 50$ years; and neighborhood-level socioeconomic status (SES) (expressed as quintiles of neighborhood income). The index year was also considered as a potential confounder. To maximize consistency of group sizes and time periods across provinces, groups were as follows: 1995/1996-1999 (reference), 2000-2004, 20052010/2012, and also 1989-1994 in MB. The $\chi^{2}$ test was used to examine the association between these potential confounders (outlined above) and each of the outcomes, and between comorbidity status and study outcome. Cox proportional hazards regression models were used to assess the influence of preexisting comorbidities (occurring on or before the index date) on the time from the index date to DMT initiation. Multivariable logistic regression models were built to examine the association between comorbidity status (grouped as $0,1,2$, and $\geq 3$ comorbidities) before the index date and the choice of initial DMT; these models included only those individuals who initiated one of the 2 injectable DMTs during follow-up and were adjusted for potential confounders (described above). Cox proportional hazards regression models were used to assess the influence of comorbidities (occurring on or after the index date) on the time from the index date to DMT initiation, with incident comorbidities occurring after the index date included as timevarying covariates. All models were adjusted for the same covariates as the logistic models.

Results from each site were pooled via a meta-analysis using random-effects models. ${ }^{17}$ Heterogeneity between sites was estimated using the $I^{2}$ statistic. $^{18}$

Complementary analyses. To test key assumptions and to fully explore the association between comorbidity status and DMT initiation, complementary analyses were conducted. First, we used an alternative measure of comorbidity status based on the number of prescription drug classes in the year before the index date. Second, we examined the association between DMT initiation and vascular comorbidity, a variable combining diabetes, hypertension, hyperlipidemia, and IHD, given reported associations of vascular comorbidity with MS outcome. ${ }^{8}$ Third, we repeated the analysis in a restricted cohort in each province with relapsing-onset MS for whom MSspecific clinical data were available. We applied the same 
Table 1 Patient characteristics at index date in each study province

\begin{tabular}{|c|c|c|c|c|c|}
\hline Characteristics at index date & British Columbia & Manitoba & Nova Scotia & Total & $p$ Value ${ }^{a}$ \\
\hline \multicolumn{6}{|l|}{ Age, $y^{b}$} \\
\hline Mean (SD) & 44.6 (13.2) & $41.4(12.7)$ & $40.6(10.5)$ & $43.1(12.7)$ & $<0.001^{\mathrm{c}}$ \\
\hline $30-39$, n (\%) & $1,537(24.9)$ & $899(29.4)$ & $460(31.4)$ & $2,896(27.1)$ & \\
\hline 40-49, n (\%) & 1,986 (32.2) & $880(28.8)$ & 493 (33.6) & $3,359(31.4)$ & \\
\hline \multicolumn{6}{|l|}{ Sex, n (\%) $)^{b, e}$} \\
\hline Female & 4,531 (73.4) & 2,238 (73.2) & $1,118(76.2)$ & $7,887(73.7)$ & $0.07^{d}$ \\
\hline Male & $1,641(26.6)$ & $820(26.8)$ & $349(23.8)$ & $2,810(26.3)$ & \\
\hline \multicolumn{6}{|l|}{ Year of index date, $n(\%)^{b, f}$} \\
\hline 2005-2012 & 2,072 (33.6) & $787(25.7)$ & $440(30.0)$ & 3,299 (30.8) & \\
\hline \multicolumn{6}{|l|}{ SES, $n(\%)^{b, g}$} \\
\hline 1 (lowest) & $1,103(17.9)$ & $622(20.3)$ & $293(20.0)$ & 2,018 (18.9) & $<0.001^{\mathrm{d}, \mathrm{e}}$ \\
\hline 2 & $1,150(18.6)$ & 671 (21.9) & $266(18.1)$ & 2,087 (19.5) & \\
\hline 3 & $1,277(20.7)$ & 549 (18.0) & 287 (19.6) & 2,113 (19.8) & \\
\hline 4 & $1,270(20.6)$ & $672(22.0)$ & $298(20.3)$ & 2,240 (20.9) & \\
\hline 5 (highest) & $1,235(20.0)$ & $544(17.8)$ & 289 (19.7) & 2,068 (19.3) & \\
\hline \multicolumn{6}{|c|}{ Follow-up (between index date and end of follow up), y } \\
\hline Total & $1,448(45.7)$ & $898(28.3)$ & $824(26.0)$ & 3,170 & \\
\hline
\end{tabular}

Abbreviations: $\mathrm{BC}=$ British Columbia; DMT = disease-modifying therapy; IQR = interquartile range; $\mathrm{MB}=$ Manitoba; $\mathrm{MS}=$ multiple sclerosis; $\mathrm{NS}=\mathrm{Nova}$ Scotia; SES = socioeconomic status.

${ }^{a} p$ Values indicate statistical significance in comparisons between the provinces.

${ }^{\mathrm{b}}$ All percentages were calculated by dividing the numbers in each category by the total number of patients with incident MS in each site.

${ }^{\mathrm{c}}$ Student $t$ test.

${ }^{\mathrm{d}}$ Chi-square test.

e Sex was not available for 1 patient in BC.

${ }^{f}$ Data were available between 1989 and 2012 for MB, 1995-2012 for NS, and 1996-2010 for BC. Incident cases in 1989-1994 were not used in the comparisons among the provinces.

${ }^{9}$ Socioeconomic information was not available for 138 patients for BC or for 34 patients for NS. Missing SES values were not used in comparisons between the provinces.

${ }^{\mathrm{h}}$ Calculation of median follow-up years for the entire cohort requires combining individual-level data from 3 provinces, which is prohibited due to regulatory and privacy issues.

analytical approach for complementary analyses as described above (Methods appendix e-1).

Statistical analyses were performed using the Statistical Package for Social Sciences (Chicago, IL), ${ }^{19} \mathrm{R}$ (version 3.0.2), ${ }^{20}$ and SAS V9.3 (SAS Institute Inc., Cary, NC).

RESULTS Study populations. Across the 3 provinces, we identified 10,698 persons with incident MS. Patients in $\mathrm{BC}$ were older than those in $\mathrm{MB}$ and $\mathrm{NS}$; however, the distributions of sex and SES were consistent across provinces (table 1). Mean age at the index date was higher among participants with comorbidities $(p<0.001$, table e-2). Half of these participants had $\geq 1$ comorbidity at the index date (table e-3).

Rates of subsequent DMT initiation. After the index date, 3,170 individuals (29.6\%) initiated a DMT. Females and 


\section{Factors \\ Comorbidity count at index date ${ }^{a}$}

Year 1

British Columbia

Manitoba

Nova Scotia

Overall

Test for heterogeneity: $\mathrm{X}^{2}=166.4 \mathrm{f}=2, p<0.001$

Year 2

British Columbia

Manitoba

Nova Scotia

Overall

Test for heterogeneity: $X^{2}=160.8, d f=2, p<0.001$

Year 5

British Columbia

Manitoba

Nova Scotia

Overall

Test for heterogeneity: $x^{2}=159.6, \mathrm{df}=2, p<0.001$

Comorbidity count during follow-up ${ }^{b}$

British Columbia

Manitoba

Nova Scotia

Overall

Test for heterogeneity:

$X^{2}=2.63, \mathrm{df}=2, p=0.27$
Adjusted hazard ratio

$(95 \% \mathrm{Cl})$

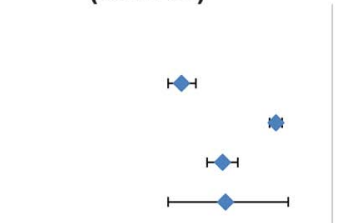


Figure 2 Each individual comorbidity at the index date and the hazard ratios (HRs) of subsequent diseasemodifying therapy (DMT) initiation ${ }^{a}$

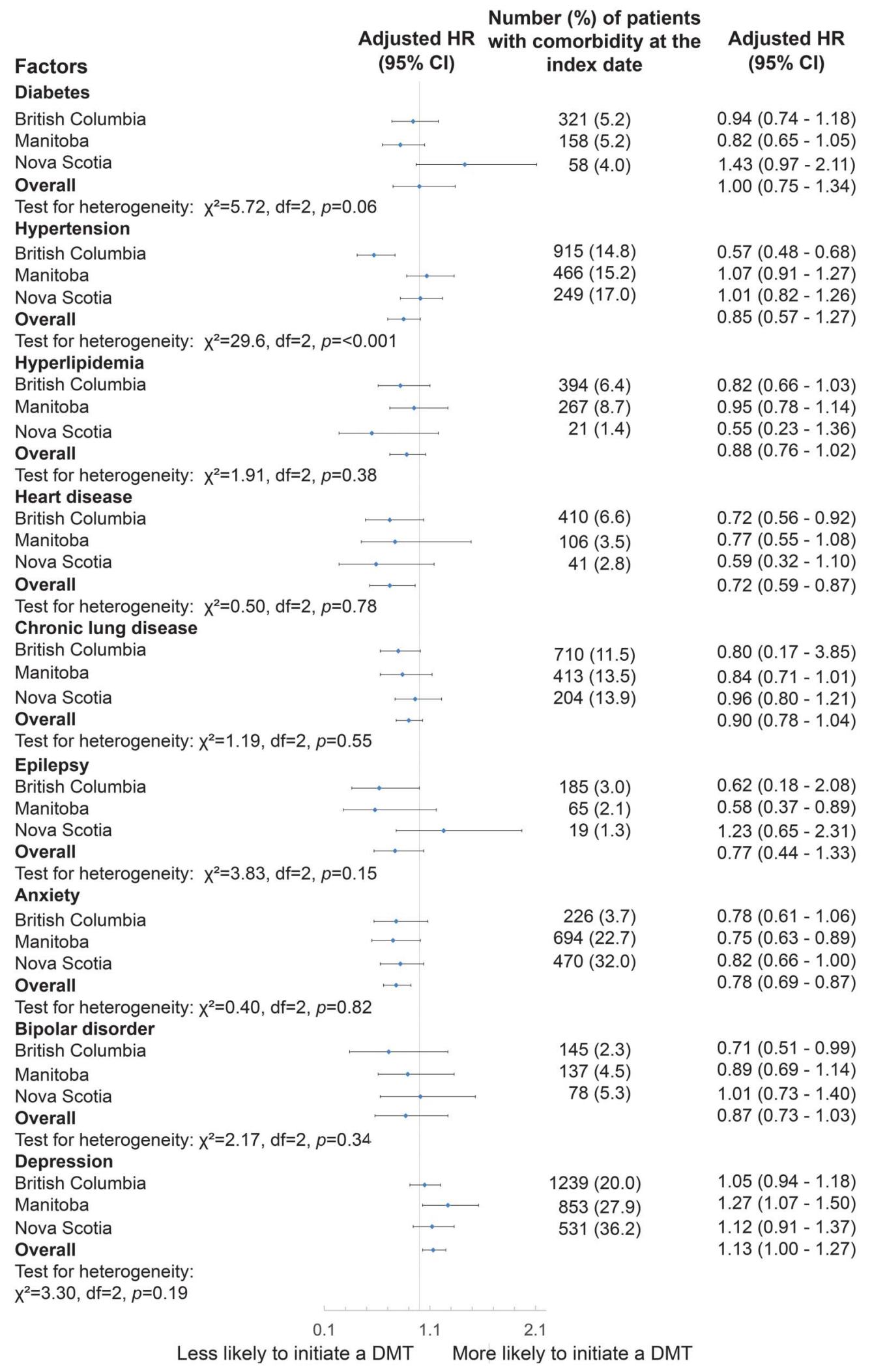

aResults were obtained from time-fixed Cox proportional hazards models. Reference group was patients without each individual comorbidity and comorbidity by the index date. Model was adjusted for age, sex, year of index date, and socioeconomic status. $\mathrm{Cl}=$ confidence interval. 
Figure 3 Total number of comorbidities by the index date and choice of initial disease-modifying therapy received

\section{Factors}

1 comorbidity $^{\mathrm{a}}$

British Columbia

Manitoba

Nova Scotia

Overall

Test for heterogeneity: $x^{2}=0.24, d f=2, p=0.89$

2 comorbidities $^{a}$

British Columbia

Manitoba

Nova Scotia

Overall

Test for heterogeneity: $x^{2}=0.23, d f=2, p=0.89$

$3+$ comorbidities $^{a}$

British Columbia

Manitoba

Nova Scotia

Overall

Test for heterogeneity:

$X^{2}=2.33, d f=2, p=0.31$

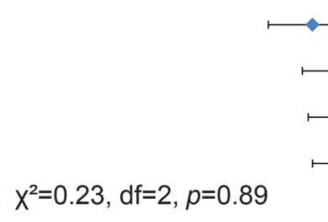

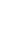

1

Adjusted odds ratio $(95 \% \mathrm{Cl})$
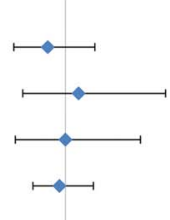

\section{9}

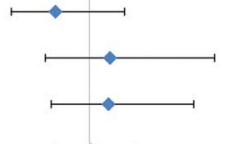

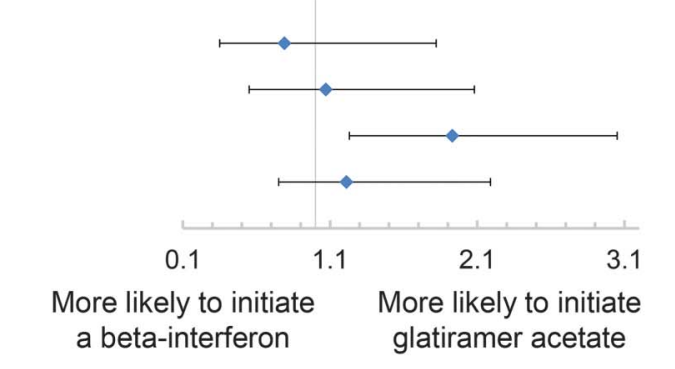

\begin{abstract}
aThe comorbidities of interest included diabetes, hypertension, hyperlipidemia, heart disease, chronic lung disease, epilepsy, anxiety, depression, and bipolar disorder. ${ }^{b}$ Reference groups were patients with no $(0)$ comorbidity by the index date. Models were adjusted for age, sex, year of index date, and socioeconomic status. 'Results were obtained from logistic regression models. Odds ratios represent the relative odds of receiving glatiramer acetate compared to the odds of receiving interferon- $\beta$ among those without comorbidities by the index date. $\mathrm{Cl}=$ confidence interval.
\end{abstract}

the patients who initiated 1 of the 2 DMTs during follow-up, neither the number of comorbidities (figure 3) nor individual comorbidities at the index date was associated with the DMT choice (data not shown). These findings were consistent after substituting comorbidity as a continuous variable to assess a dose-response type effect (data not shown). In all models, none of the covariates was associated with the choice of initial DMT (data not shown).

Complementary analyses. When the number of prescription drug classes in the year before the index date was used instead of the number of comorbidities, the effect estimate was in the same direction, although the findings did not reach statistical significance (figures e5 and e-6). Combined vascular comorbidity was not associated with DMT initiation. Restricting our cohort to those with MS-specific clinical data resulted in 3,686 individuals with incident relapsing-onset MS (table e-1). Findings in this subcohort were consistent with the primary analyses (figures e-7 and e-8).

DISCUSSION In this cohort study of 10,698 incident MS cases, we observed effects of comorbidities on the initiation of a DMT for MS. We found that the greater the number of comorbidities, the lower the likelihood that a DMT for MS was started. When examining individual comorbidities, IHD and anxiety were associated with a reduction in the likelihood of subsequent DMT initiation.

We were unable to find previous studies that examined the association between comorbidity and DMT initiation or choice of initial DMT in MS. However, our observation that as the number of comorbidities increased, the likelihood of DMT initiation decreased, is consistent with other chronic diseases such as cancer and diabetes, in which increasing comorbidity burden delays treatment initiation. ${ }^{11,21-23}$ For primary care physicians and patients, multiple chronic conditions may serve as competing demands on time or act as barriers that may influence access to and decisions regarding treatment. ${ }^{24,25}$ In the context of our study in Canada, where DMT treatment is initiated by a specialist, this delay in treatment initiation may reflect diagnostic delays due to the presence of comorbidity, as diagnostic delays have been shown in the US-based North American Research Committee on MS registry. ${ }^{7}$ 
Similar diagnostic delays in the presence of comorbidity have also been shown in rheumatoid arthritis ${ }^{26}$ and cancer. ${ }^{27}$

We found that IHD and anxiety were strongly associated with a decreased likelihood of initiating a DMT. Other conditions, such as hyperlipidemia, chronic lung diseases, and bipolar disorder, also exhibited similar associations, though none reached significance, possibly because a smaller number of individuals were affected. A possible reason for this association in patients with IHD, one also likely to be present for patients with hyperlipidemia and chronic lung diseases, is that they are already burdened with multidrug regimens. This greater number of concurrent drug therapies is likely to affect patients' and physicians' decisions regarding initiating another treatment. Perceived benefits of therapy may also be less when multiple chronic conditions affect health status.

Our findings regarding the negative impact of anxiety and bipolar disorder on DMT initiation are consistent with findings in other chronic diseases. ${ }^{21,28}$ Mental health comorbidities can impair communication between patients and clinicians, interfere with self-management and the ability to follow treatment recommendations, or amplify concerns regarding drug treatment. ${ }^{29,30}$ Additionally, patients with an anxiety disorder may decline treatment when offered due to needle phobia or fear of adverse effects; needle phobia has been suggested as a predictor of nonadherence or discontinuation of MS drugs in previous reports. ${ }^{31-33}$ Thus identification of patients with preexisting anxiety is important for health professionals to provide appropriate and sufficient medical interventions. Unexpectedly, we found comorbid depression to be associated with an increased likelihood of initiating a DMT in our study, although the hazard ratio only reached marginal statistical significance. This finding contrasts with studies that have reported a decreased likelihood of treatment initiation in patients with diabetes or cancer who had comorbid depression. $^{21,28}$ We can speculate that patients with preexisting depression may have had more active (MS) disease compared to those who did not, ${ }^{34}$ prompting the decision to initiate DMT treatment. However, we do not know the status of depression (active, in remission) at the time treatment decisions were made and further study will be needed to explore this possible relationship. We did not find an association between presence of depression and the choice of DMT received. This is of interest given the early safety concerns regarding a possible increased risk of suicide and depression in relation to interferon- $\beta$ use, ${ }^{35-37}$ although subsequent studies had mixed findings. ${ }^{38}$

We observed variation across provinces, highlighting the value of a multisite study and pooled analyses.
For instance, the increased likelihood of initiating a DMT associated with the presence of depression is mainly attributable to the association between depression and DMT initiation in Manitoba; hypertension was associated with an almost 50\% reduced likelihood of DMT initiation in British Columbia but this was not observed in Manitoba or Nova Scotia. This apparent difference in prescribing practices across provinces may reflect the gap in knowledge regarding the effectiveness and safety of DMTs in individuals with MS and comorbid conditions as such individuals are typically excluded from clinical trials. Findings such as this highlight the need to better understand the optimal treatment approaches in patients with MS and comorbidities, and to develop an evidence base to better support clinical decision-making in this population.

Our study's strengths include that it was population-based and we identified a large study population using a validated MS case definition. However, our study also had limitations. For example, comorbidity onset could be misclassified in patients who infrequently access the health system, possibly underestimating or overestimating the impact of comorbidities on DMT use. Our case definitions for comorbidity were highly specific, but definitions for IHD and anxiety were less sensitive, ${ }^{15,39}$ thus we have not captured all cases of each comorbidity, which might be expected to bias our findings toward the null. Individuals with MS onset late in the study period might not have had time to meet our case definition. We were unable to determine whether depression or anxiety reflected early prodromal symptoms of MS or occurred independently. However, there are no data that suggest that MS treatment decisions would differ according to the presumed etiology of an existing mood disturbance. The presence of these conditions is relevant if they delay initiation of a DMT in MS, regardless of the etiology. The mean age at MS diagnosis was higher than reported in some studies, but is comparable to that reported in other studies using similar methods. ${ }^{13,40} \mathrm{~A}$ later age of diagnosis may lead to a higher prevalence of comorbidity at diagnosis but would not affect the association between comorbidity and DMT initiation. Indicators of MS disease activity or comorbid condition severity were not available to us and would be of value to explore in future studies where this level of detail is available. The number of years of data available varied by province. However, all data began before the DMTs first became available in Canada and follow-up periods were substantially longer than the median time to DMT initiation. The different follow-up times would not be expected to affect our findings. Finally, a small number of patients who did not initiate DMT may not have been eligible for 
treatment under their provincial governments' schemes for drug reimbursement; however, we were able to confirm our main findings in subgroups where these clinical data were available. Nonetheless, our findings require replication.

This multi-province, population-based cohort study revealed that comorbidities influence the use of DMT in incident MS. As the number of current comorbidities increased, the likelihood of DMT initiation decreased. Mental comorbidities such as anxiety had a significant impact on subsequent DMT initiation. Individuals with MS and multiple comorbidities likely require more health services and more complex health management strategies. A better understanding of the effects of comorbidity on the effectiveness and safety of DMTs is needed to support clinical decisionmaking, as our findings suggest that individuals with these conditions may be treated differently with respect to access to MS-specific drug therapies in the absence of supporting evidence.

\section{AUTHOR CONTRIBUTIONS}

The corresponding author (R.A.M.) takes responsibility for the integrity of the data and the accuracy of the data analysis. The analysts and principal investigators at each site had full access to the data at each site (BC: Helen Tremlett, Feng Zhu, Tingting Zhang; MB: Ruth Ann Marrie, Stella Leung; NS: John Fisk, Yan Wang). Ruth Ann Marrie, John Fisk, and Helen Tremlett designed the study and obtained funding. All authors contributed to the interpretation of the data. Tingting Zhang drafted the manuscript. All authors revised the manuscript and approved the final version to be published.

\section{ACKNOWLEDGMENT}

All inferences, opinions, and conclusions drawn in this publication are those of the authors and do not reflect the opinions or policies of the Data Stewards. No official endorsement by Manitoba Health, Population Data BC, Pharmanet, or the Regie D'Assurance Maladie du Quebec is intended or should be inferred. Some data used in this report were made available by Health Data Nova Scotia of Dalhousie University. Although this research is based on data obtained from the Nova Scotia Department of Health and Wellness, the observations and opinions expressed of those of the authors and do not represent those of either Health Data Nova Scotia or the Department of Health and Wellness. The authors thank the following contributors: Patricia Caetano, PhD (University of Manitoba, policy consultant); Nicholas Hall, BSc (University of Manitoba, study coordinator); Yan Wang (Dalhousie University, analytic support); Larry Svenson, BSc (University of Alberta, Collaborator).

\section{STUDY FUNDING}

Supported in part by the Canadian Institutes of Health Research (CIBG 101829), the Rx \& D Health Research Foundation, a Don Paty Career Development award from the Multiple Sclerosis Society of Canada (to R.A.M.), and Manitoba Research Chair from Research Manitoba (to R.A.M.). The funding sources had no role in the study design, collection, analysis or interpretation of the data, or in the decision to submit the article for publication. The Article Processing Charge was paid by CIHR.

\section{DISCLOSURE}

T. Zhang receives a Post-Doctoral Fellowship Award from the Multiple Sclerosis Society of Canada (2014-2016). H. Tremlett is funded by the Multiple Sclerosis Society of Canada (Don Paty Career Development Award) and is a Michael Smith Foundation for Health Research Scholar and the Canada Research Chair for Neuroepidemiology and Multiple Sclerosis. She has received research support from the National Multiple Sclerosis
Society, the Canadian Institutes of Health Research, and the UK MS Trust; speaker honoraria and/or travel expenses to attend conferences from the Consortium of MS Centres (2013), the National MS Society (2012, 2014), Bayer Pharmaceuticals (2010), Teva Pharmaceuticals (2011), ECTRIMS (2011, 2012, 2013, 2014), UK MS Trust (2011), the Chesapeake Health Education Program, US Veterans Affairs (2012), Novartis Canada (2012), Biogen Idec (2014), and American Academy of Neurology (2013, 2014, 2015). Unless otherwise stated, all speaker honoraria are either donated to an MS charity or to an unrestricted grant for use by her research group. S. Leung, F. Zhu, and E. Kingwell report no disclosures relevant to the manuscript. J. Fisk receives research grant and training program support from the Canadian Institutes of Health Research, the National Multiple Sclerosis Society, and the Multiple Sclerosis Society of Canada; and has received speaker honoraria from EMD Serono $(2013,2014)$. V. Bhan has received honoraria and consulting fees from Biogen Idec, EMD Serono, Genzyme, Novartis, Roche, and Teva Neurosciences. T. Campbell has received honoraria from Biogen Idec Canada, Teva Canada Innovation, EMD Serono, Genzyme, and Novartis; support for travel from Biogen Idec, Teva Canada Innovation, EMD Serono, and Genzyme; grant support from Biogen Idec Canada Inc. and Novartis; and research support from Biogen Idec Canada Inc. K. Stadnyk reports no disclosures relevant to the manuscript. B. Yu receives research funding from Health Science Centre Foundation, Canadian Institutes of Health Research, Gilead Sciences, Canadian International Development Agency, the Multiple Sclerosis Society of Canada, and National Multiple Sclerosis Society (USA). R.A. Marrie receives research funding from Canadian Institutes of Health Research, Research Manitoba, Multiple Sclerosis Society of Canada, Multiple Sclerosis Scientific Foundation, National Multiple Sclerosis Society, and Rx \& D Health Research Foundation, and has conducted clinical trials funded by Sanofi-Aventis. Go to Neurology.org for full disclosures.

Received July 24, 2015. Accepted in final form December 21, 2015.

\section{REFERENCES}

1. Leary SM, Porter B, Thompson AJ. Multiple sclerosis: diagnosis and the management of acute relapses. Postgrad Med J 2005;81:302-308.

2. Filippini G, Del Giovane C, Vacchi L, et al. Immunomodulators and immunosuppressants for multiple sclerosis: a network meta-analysis. Cochrane Database Syst Rev 2013; 6:CD008933.

3. Simpson RJ, McLean G, Guthrie B, Mair F, Mercer SW. Physical and mental health comorbidity is common in people with multiple sclerosis: nationally representative cross-sectional population database analysis. BMC Neurol 2014;14:128.

4. Rochon PA, Katz JN, Morrow LA, et al. Comorbid illness is associated with survival and length of hospital stay in patients with chronic disability: a prospective comparison of three comorbidity indices. Med Care 1996;34: 1093-1101.

5. Tettey P, Simpson S Jr, Taylor B, et al. An adverse lipid profile is associated with disability and progression in disability, in people with MS. Mult Scler 2014;20:1737-1744.

6. Moccia M, Lanzillo R, Palladino R, et al. The Framingham cardiovascular risk score in multiple sclerosis. Eur J Neurol 2015;22:1176-1183.

7. Marrie RA, Horwitz R, Cutter G, Tyry T, Campagnolo D, Vollmer T. Comorbidity delays diagnosis and increases disability at diagnosis in MS. Neurology 2009;72:117-124.

8. Marrie RA, Rudick R, Horwitz R, et al. Vascular comorbidity is associated with more rapid disability progression in multiple sclerosis. Neurology 2010;74:1041-1047.

9. Bhardwaj SS, Chalasani N. Lipid-lowering agents that cause drug-induced hepatotoxicity. Clin Liver Dis 2007; 11:597-613. 
10. FDA Drug Safety Communication: Revised recommendations for cardiovascular monitoring and use of multiple sclerosis drug Gilenya (fingolimod). Available at: http:// www.fda.gov/Drugs/DrugSafety/ucm303192.htm. Accessed September 21, 2015.

11. Sogaard M, Thomsen RW, Bossen KS, Sorensen HT, Norgaard M. The impact of comorbidity on cancer survival: a review. Clin Epidemiol 2013;5(suppl 1):3-29.

12. Voorham J, Haaijer-Ruskamp FM, Wolffenbuttel BH, de Zeeuw D, Stolk RP, Denig P. Differential effects of comorbidity on antihypertensive and glucose-regulating treatment in diabetes mellitus: a cohort study. PLoS One 2012;7:e38707.

13. Kingwell E, Zhu F, Marrie RA, et al. High incidence and increasing prevalence of multiple sclerosis in British Columbia, Canada: findings from over two decades (1991-2010). J Neurol 2015;262:2352-2363.

14. Marrie RA, Fisk JD, Stadnyk KJ, et al. The incidence and prevalence of multiple sclerosis in Nova Scotia, Canada. Can J Neurol Sci 2013;40:824-831.

15. Marrie RA, Fisk JD, Yu BN, et al. Mental comorbidity and multiple sclerosis: validating administrative data to support population-based surveillance. BMC Neurol 2013;13:16

16. Marrie RA, Yu BN, Leung $S$, et al. The utility of administrative data for surveillance of comorbidity in multiple sclerosis: a validation study. Neuroepidemiology 2013;40 85-92.

17. Riley RD, Higgins JP, Deeks JJ. Interpretation of random effects meta-analyses. BMJ 2011;342:d549.

18. Higgins JP, Thompson SG, Deeks JJ, Altman DG. Measuring inconsistency in meta-analyses. BMJ 2003;327: 557-560.

19. IBM Corp. Released. IBM SPSS Statistics for Windows, Version 22.0. Armonk, NY: IBM Corp.; 2013.

20. R Core Team. R: A Language and Environment for Statistical Computing [computer program]. Version 3.0.2. Vienna, Austria: R Foundation for Statistical Computing; 2013.

21. Vitry AI, Roughead EE, Preiss AK, et al. Influence of comorbidities on therapeutic progression of diabetes treatment in Australian veterans: a cohort study. PLoS One 2010;5:e14024.

22. Parchman ML, Pugh JA, Romero RL, Bowers KW. Competing demands or clinical inertia: the case of elevated glycosylated hemoglobin. Ann Fam Med 2007;5:196-201.

23. Lee L, Cheung WY, Atkinson E, Krzyzanowska MK. Impact of comorbidity on chemotherapy use and outcomes in solid tumors: a systematic review. J Clin Oncol 2010;29:106-117.

24. Kingwell E, Bajdik C, Phillips N, et al. Cancer risk in multiple sclerosis: findings from British Columbia. Can Brain 2012;135:2973-2979.

25. Jaen CR, Stange KC, Nutting PA. Competing demands of primary care: a model for the delivery of clinical preventive services. J Fam Pract 1994;38:166-171.
26. Tavares R, Pope JE, Tremblay JL, et al. Time to diseasemodifying antirheumatic drug treatment in rheumatoid arthritis and its predictors: a national, multicenter, retrospective cohort. J Rheumatol 2012;39:2088-2097.

27. Winget M, Hossain S, Yasui Y, Scarfe A. Characteristics of patients with stage III colon adenocarcinoma who fail to receive guideline-recommended treatment. Cancer 2010; 116:4849-4856.

28. Boyd CA, Benarroch-Gampel J, Sheffield KM, Han Y, Kuo YF, Riall TS. The effect of depression on stage at diagnosis, treatment, and survival in pancreatic adenocarcinoma. Surgery 2012;152:403-413.

29. Pan A, Lucas M, Sun Q, et al. Increased mortality risk in women with depression and diabetes mellitus. Arch Gen Psychiatry 2011;68:42-50.

30. Koroukian SM, Xu F, Beaird H, Diaz M, Murray P, Rose JH. Complexity of care needs and unstaged cancer in elders: a population-based study. Cancer Detect Prev 2007;31:199-206.

31. Tremlett HL, Oger J. Interrupted therapy: stopping and switching of the beta-interferons prescribed for MS. Neurology 2003;61:551-554.

32. Cox D, Stone J. Managing self-injection difficulties in patients with relapsing-remitting multiple sclerosis. J Neurosci Nurs 2006;38:167-171.

33. Devonshire V, Lapierre Y, Macdonell R, et al. The Global Adherence Project (GAP): a multicenter observational study on adherence to disease-modifying therapies in patients with relapsing-remitting multiple sclerosis. Eur J Neurol 2011;18:69-77.

34. Zabad RK, Patten SB, Metz LM. The association of depression with disease course in multiple sclerosis. Neurology 2005;64:359-360.

35. Fragoso YD, Frota ER, Lopes JS, et al. Severe depression, suicide attempts, and ideation during the use of interferon beta by patients with multiple sclerosis. Clin Neuropharmacol 2010;33:312-316.

36. Mohr DC, Likosky W, Boudewyn AC, et al. Side effect profile and adherence to in the treatment of multiple sclerosis with interferon beta-1a. Mult Scler 1998;4:487-489.

37. Neilley LK, Goodin DS, Goodkin DE, Hauser SL. Side effect profile of interferon beta-1b in MS: results of an open label trial. Neurology 1996;46:552-554.

38. Patten SB, Francis G, Metz LM, Lopez-Bresnahan M, Chang P, Curtin F. The relationship between depression and interferon beta-1a therapy in patients with multiple sclerosis. Mult Scler 2005;11:175-181.

39. Marrie RA, Yu BN, Leung S, et al. Prevalence and incidence of ischemic heart disease in multiple sclerosis: a population-based validation study. Mult Scler Relat Disord 2013;2:355-361.

40. Mackenzie IS, Morant SV, Bloomfield GA, MacDonald TM, O'Riordan J. Incidence and prevalence of multiple sclerosis in the UK 1990-2010: a descriptive study in the General Practice Research Database. J Neurol Neurosurg Psychiatry 2014;85:76-84. 


\section{Neurology}

\section{Examining the effects of comorbidities on disease-modifying therapy use in multiple sclerosis}

Tingting Zhang, Helen Tremlett, Stella Leung, et al.

Neurology 2016;86;1287-1295 Published Online before print March 4, 2016

DOI 10.1212/WNL.0000000000002543

\section{This information is current as of March 4, 2016}

\section{Updated Information \& Services}

Supplementary Material

\section{References}

Citations

\section{Subspecialty Collections}

Permissions \& Licensing

Reprints including high resolution figures, can be found at: http://n.neurology.org/content/86/14/1287.full

Supplementary material can be found at: http://n.neurology.org/content/suppl/2016/03/04/WNL.0000000000002 543.DC1

http://n.neurology.org/content/suppl/2016/03/04/WNL.0000000000002 543.DC2

This article cites 33 articles, 10 of which you can access for free at: http://n.neurology.org/content/86/14/1287.full\#ref-list-1

This article has been cited by 5 HighWire-hosted articles: http://n.neurology.org/content/86/14/1287.full\#\#otherarticles

This article, along with others on similar topics, appears in the following collection(s):

Cohort studies

http://n.neurology.org/cgi/collection/cohort_studies

Multiple sclerosis

http://n.neurology.org/cgi/collection/multiple_sclerosis

Information about reproducing this article in parts (figures,tables) or in its entirety can be found online at:

http://www.neurology.org/about/about_the_journal\#permissions

Information about ordering reprints can be found online:

http://n.neurology.org/subscribers/advertise

Neurology ${ }^{\circledR}$ is the official journal of the American Academy of Neurology. Published continuously since 1951, it is now a weekly with 48 issues per year. Copyright @ 2016 American Academy of Neurology. All rights reserved. Print ISSN: 0028-3878. Online ISSN: 1526-632X.

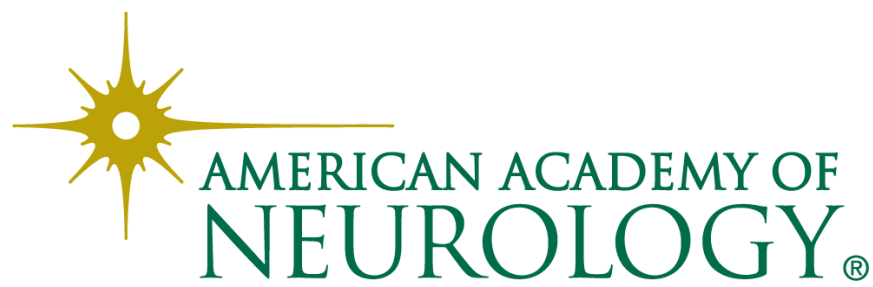

